\title{
УПРАВЛЕНИЕ КАЧЕСТВОМ РАБОЧЕЙ СИЛЫ В ЗДРАВООХРАНЕНИИ КАК СОСТАВЛЯЮЩАЯ КАЧЕСТВА ЖИЗНИ НАСЕЛЕНИЯ РФ
}

\begin{abstract}
Аннотация: в статье рассматривается взаимосвязь качества жизни, как категории наичональной безопасности, качества питания и качества здравоохранения или здоровья. Подчеркивается, что посредством зависимости здоровья населения от качества продуктов питания категория «здоровье» связана и с продовольственной безопасностью.Также, в статье подчеркивается, что качество здравоохранения предполагает качество медицинской помоши, которое невозможно без качества рабочей силь, в связи с чем исследуются и анализируются качественные показатели рабочей силь в здравоохранении. В статье отмечается, что, основной задачей в области управления качеством рабочей силь в здравоохранении является создание модели эффективного управления повышением качества способностей человека к труду, направленной на повышение качества оказываемой медицинской помощи. Обосновывается, что основными задачами в области управления качеством рабочей силь в здравоохранении являются создание модели эффективного управления повышением качества способностей человека к труду, направленной на повышение качества оказываемой медицинской помощчи (медицинских услуг) и разработка мероприятий по их дальнейшему улучшению.
\end{abstract}

Ключевые слова: здоровье, здравоохранение, качество жизни, начииональная безопасность, рабочая сила, управление качеством, трудовой потенциал, конкурентоспособность, человеческий капитал, квалификачия персонала.

Review: the article concerns the correlation of the living standard as a national security category, quality of foodstuffs and healthcare or health. It is pointed out that due to dependency of health of the population upon the quality of foodstuffs, the category of "health" is related to the foodstuffs security. It is also noted that the quality health care presupposes quality of medical aid, which cannot be achieved without the quality of working force, that is why the author studies the quality markers of working force in the sphere of healthcare. It is noted in the article that the main goal in the sphere of managing working force in the sphere of healthcare is to form an efficient model for the improvement of healthcare quality (medical services) and the measures for its further improvement. Keywords: health, health care, living standard, national security, working force, quality management, working potential, competition capability, human capital, qualification of the personnel.

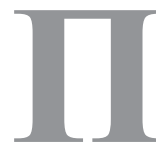
рослеживая тенденцию развития определения качества жизни, следует отметить, что понятие «качество жизни», «уровень жизни», «условия жизни», «благосостояние населения» и другие аналогичные понятия используются для характеристики благополучия населения. Под уровнем жизни понимают обеспеченность населения необходимыми материальными благами и услугами, достигнутый уровень 
их потребления и степень удовлетворения разумных (рациональных) потребностей. В широком смысле понятие «уровень жизни населения» включает еще условия жизни, труда и занятости, быта и досуга, его здоровье, образование, природную среду обитания и т.д. В данном случае чаще всего употребляется термин «качество жизни» ${ }^{1}$.

Качество жизни населения является национальной идеей и составной частью национальной безопасности, в то время как структура качества жизни включает следующие составляющие: качество питания, одежды, комфорт жилища, качество здравоохранения, образования, сферы обслуживания, окружающей среды, досуга, степень удовлетворения потребностей в содержательно общении, знаниях, творческом труде, а также уровень стрессовых ситуаций, структура расселении и т.д ${ }^{2}$.

Таким образом, качество жизни тесно связано с качеством питания и категорией здоровья, которое представляет такое качество жизненного процесса, которое становится оптимальным, соответствующим его собственным закономерностям осуществления в природно-социальной среде, когда оно обогащается необходимым внутренним, своим смыслом жизни, миром конкретного субъекта, выступая для последнего адекватной гигиенической средой, здоровым образом жизни ${ }^{3}$.

Исследуя отечественные и зарубежные методологические подходы к оценке качества жизни, необходимо выделить особую значи-

\footnotetext{
${ }^{1}$ Старовертов О.В. Условия жизни и межгрупповая мобильность/Экономика и математические методы. 1997. - №4. - с. 64.

2 Российская социологическая энциклопедия. Под общей редакцией академика РАН Г.В. Осипова. М. Инфра-М, 1998

${ }^{3}$ Сидоров П.И., Ганжин В.Т. Общественное здоровье и социальные недуги. М.,АГМА, 1996.
}

мость тех показателей, которые отражают концептуальную взаимосвязь и взаимозависимость с качеством продуктов питания и это, прежде всего, показатель здоровья, характеризующий физическое, социальное и психическое состояние населения.

Здоровье ${ }^{4}$ - важнейший фактор общественного развития во всех экономических системах. Состояние здоровья населения на макроуровне характеризует здоровье нации или общественное здоровье. Исходной «клеточкой» общественного здоровья является здоровье отдельного человека. Состояние здоровья нации влияет на количественную и качественную характеристику трудовых ресурсов, социальную, экономическую и трудовую активность населения. Последние, в свою очередь, оказывают непосредственное влияние на уровень важнейших макроэкономических показателей. Здоровье нации является одним из основных условий для современного экономического роста. Любая общность граждан, отличающаяся высоким качеством жизни, одновременно характеризуется и высоким «качеством» здоровья. Фактор здоровья становится показателем достигнутого уровня качества жизни людей, социально-экономического развития общества.

Оценка состояния здоровья имеет как демографический, так и экономический аспект. К числу демографических показателей относятся: уровень смертности, интенсивность смертности, ожидаемая продолжительность жизни на момент рождения и др. Экономическая оценка здоровья населения производится с точки зрения получения экономического эффекта в результате проведенных мер, направленных на улучшение

\footnotetext{
${ }^{4}$ Акопян А.С. Индустрия здоровья: экономика и управление: Пособие для вузов/ А.С. Акопян, Ю.В. Шиленко, Т.В. Юрьева; под ред. Л.Е. Сырцовой. - М.: Дрофа, 2003.
} 
охраны здоровья. Для этих целей рассчитываются следующие показатели: экономический эффект от снижения заболеваемости с временной нетрудоспособностью, экономический эффект от снижения заболеваемости в пересчете на одного работающего и в целом по стране, оценка финансовых результатов за счет снижения уровня инвалидности и др.

Если в 90-е годы состояние здоровья населения России характеризовалось негативными тенденциями, то в последнее десятилетие ситуация начала меняться в лучшую сторону. Стала увеличиваться продолжительность жизни: в $2005^{1}$ году у мужчин она составляла 58,9 лет, у женщин - 72,5 года. В 2010 г., соответственно, 53,1 и 74,9 лет, а в 2011 г.- 64 и 75,6лет. По продолжительности жизни мужчин Россия занимает 134-е место в мире и 100-е место по продолжительности жизни женщин. Пока еще высока общая заболеваемость населения, но смертность на 1000 человек снизилась с 9,4человек в 2005 г. до 7,1 в 2011 г., при этом среди мужчин с 14,4 до 10,6 человек, среди женщин с 3,8 до 3 человек. Среди основных причин заболеваемости и смертности специальный представитель генерального директора Всемирной Организации Здоровья в России называет нездоровое питание, курение, потребление некачественного алкоголя.

В рамках качества жизни существует тесная взаимосвязь между структурой питания человека и состоянием его здоровья. Например, неполноценное, несбалансированное, малокалорийное или низкокачественное питание неизбежно ведет к ухудшению здоровья людей4. Качество питания и его структура - важнейшие факторы, определяющие здоровье населения. Правильное питание обеспечивает нормальный рост и развитие детей, способствует профилактике заболева-

${ }^{1}$ Демографический ежегодник России. М.,Росстат,2012. ний, продлению жизни людей, повышению работоспособности и создает условия для адекватной адаптации к окружающей среде.

Взаимосвязь между качеством питания и здоровьем населения предполагает также взаимосвязь между здоровьем и продовольственной безопасностью.

В проекте федерального закона «О продовольственной безопасности РФ» и в законе о качестве и безопасности пищевых продуктов под продовольственной безопасностью понимается физическая и экономическая доступность продовольствия, гарантии качества и безопасности пищевых продуктов ${ }^{2}$, т. е. продовольственная безопасность является комплексным понятием, заключающим в себе как минимум два смысла: первый связан с чисто экономическим процессом «продовольственного обеспечения»; второй вызван важностью качественной составляющей для обеспечения качества жизни, продовольственного обеспечения для поддержания национальной безопасности в ее внутреннем и внешнем проявлениях.

Продовольственная безопасность является важнейшим составным элементом национально-государственной безопасности и в этом качестве характеризует не только экономическую, но и политическую независимость существующей системы, ее способность обеспечивать потребности своих граждан без ущерба для национально-государственной безопасности.

Способность государства обеспечить продовольственную безопасность страны в случае полного или частичного прекращения внешних продовольственных поставок определяет ее продовольственную

\footnotetext{
${ }^{2}$ Федеральный закон РФ № 29 от 02.01.2004 г «О качестве и безопасности пищевых продуктов» Проект Ф3 «О продовольственной безопасности РФ» M., 1999.
} 
независимость. Т.е. продовольственная независимость - это способность экономики страны обеспечить необходимый уровень производства продуктов питания в случае полного или частичного прекращения внешних продовольственных поставок.

Ученые в определение понятия продовольственной безопасности включают фактор независимости страны от импорта, измеряемый уровнем ее самообеспеченности сельскохозяйственной продукцией, а в качестве обеспечивающего условия - защиту своих товаропроизводителей, считая для России желательным продовольственное самообеспечение в пределах 80-85\%, а критическим - 75\% ${ }^{1}$.

Качество здравоохранения, входящее в структуру качества жизни, предполагает качество медицинской помощи, которое невозможно без качества рабочей силы.

Термин «рабочая сила» используется, по крайней мере, в трех значениях. Последователи первого подхода определяют рабочую силу как совокупность физических и духовных способностей, которые используются в процессе труда при создании товаров и услуг. ${ }^{2}$ В рамках данного подхода можно выделить два понимания категории «рабочая сила». К сторонникам первого понимания можно отнести связь качества рабочей силы с образовательным и профессионально-квалификационным уровнем.

Таким образом, рабочая сила с качественной стороны характеризуется уровнем профессионально-квалификационной под-

\footnotetext{
${ }^{1}$ Емельянов А. Продовольственная бедность населения России: истоки и пути преодоления / А. Емельянов // Экономист. - 2003. - №10. - С.80; Есипов В.Е., Маховикова Г.А. Внутренние и внешние угрозы продовольственной безопасности России. - СПб.: Изд. СПб. Гос. Университета экономики и финансов, 2005. - С. 24 2 Дмитриев Ю. Качество рабочей силы: сущность, мера управления. Минск, 2008.с.36
}

готовки, производственного опыта, навыков, научно-технических знаний ${ }^{3}$. Также качество рабочей силы определяется через личностные элементы, такие как знания, опыт, навыки и другие составляющие квалификации.. ${ }^{4}$

В рамках второго понимания «качество рабочей силы - это совокупность свойств человека, проявляющихся в процессе труда, и включают в себя квалификацию, личностные характеристики работника: его физиологические и социально-психологические особенности (состояние здоровья, умственные способности), а также адаптированность, в том числе гибкость, мобильность, мотивируемость, инерционность, профориентиро-

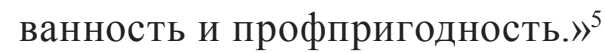

Сторонники второго подхода под рабочей силой понимают часть трудоспособного населения, занятую или ищущую работу. То есть, по сути происходит отождествление рабочей силы непосредственно с человеком. Этот подход не совсем правомерен, так как рабочая сила - это одна из сторон личности. Ее функция, идеализирующая часть природных способностей и сформированных в процессе обучения и трудовой деятельности черт.

Иногда под рабочей силой подразумеваются работники вообще или работники конкретного предприятия ${ }^{6}$ С данной позиции человек рассматривается как носитель способностей качеств, которые могут производительно использоваться в процессе труда. В данной трактовке это понятие тесно

\footnotetext{
${ }^{3}$ Косаев А.Г. Трудовой потенциал и занятость в условиях интенсификации. М.. Наука, 1990

${ }^{4}$ Дмитриев Ю. Качество рабочей силы: сущность, мера управления. Минск, 2008

5 Экономика труда и социально-трудовые отношения. Под ред. Г.Г.Меликьяна, Р.П.Колосовой. М.. МГУ,2000.С.273

${ }^{6}$ Рофе А. О содержании понятий трудовые ресурсы и рабочая сила.// Человек и труд. 1997, №10.C.23-26
} 


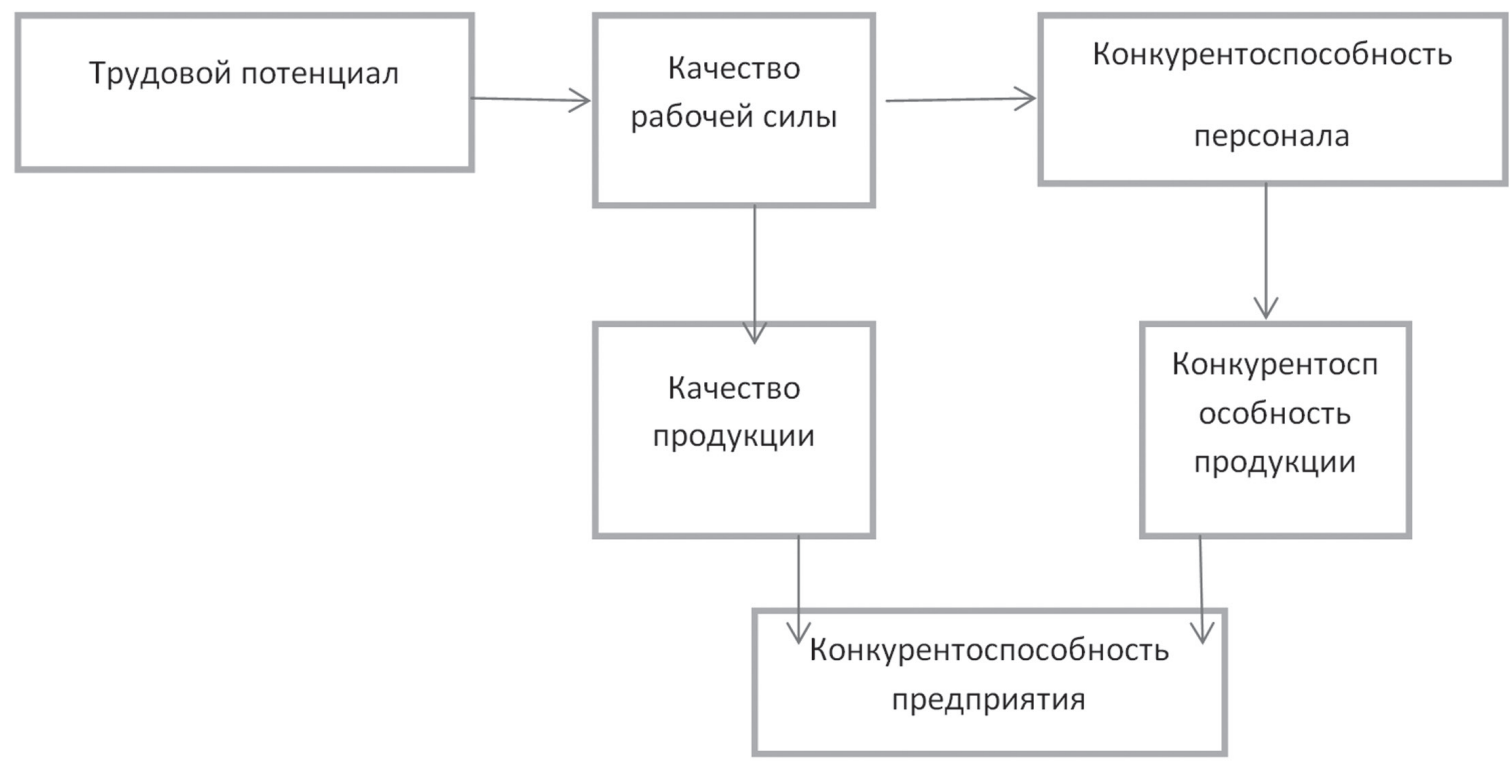

Рисунок 1. Взаимосвязь категорий трудовой потенциал, рабочая сила и конкурентоспособность связано с понятием «персонал». Персонал это категория работников, объединенных по признаку принадлежности к организации или принадлежности к профессии.

Таким образом, рабочая сила - это взятые в единстве:

1. Совокупность физических и духовных способностей человека, т. е. его трудоспособность ${ }^{1}$. 2. Способности, которые используются в процессе труда, при создании товаров и услуг.

В результате, рабочая сила - это функционирующие способности к труду или способности человека к труду, которые становятся рабочей силой лишь при участии ее носителя в общественном производстве. Следовательно, функциональная рабочая сила всегда связана с определенным местом ее приложения: конкретной отраслью хозяйства, объединением, предприятием, рабочим местом. ${ }^{2}$ Т.е. качество рабочей силы

\footnotetext{
${ }^{1}$ Журавлев П.В., Одегов Ю.Г., Волгин Н.А. Управление человеческими ресурсами: опыт индустриально развитых стран. М., Экзамен, 2002.С.108

${ }^{2}$ Хлопова Т.В. Развитие трудового потенциала конкурентоспособность работников в современных условиях. Методология и практика исследования. Иркутск, БГУЭП, 2004. С.8
} можно рассматривать на различных уровнях: на уровне страны и регионов; на уровне отраслей; на уровне предприятия; индивидуальное качество.

В западной литературе качество рабочей силы часто идентифицируется с понятием «человеческий капитал». Еще одна категория близкая к понятию «качество рабочей силы» - это трудовой потенциал. Следует заметить, что их отождествлять нельзя, т.к. в категории трудовой потенциал отражаются не только задействованные в производстве способности к труду, но и нереализованные потенции, тогда как в качестве рабочей силы - только задействованные способности. Как считают некоторые специалисты трудовой потенциал - абсолютная характеристика качества рабочей силы без соотнесения с потенциалом конкретного рабочего места ${ }^{3}$.

Взаимосвязь трудового потенциала, качества рабочей силы и конкурентоспособности можно выразить схематически (рис.1).

Проведенный анализ категории качества рабочей силы позволяет выявить структур-

\footnotetext{
${ }^{3}$ Миляева Л.Г. Оценка конкурентоспособности кадров. // ЭКО,2000.№3.C.172-175
} 
Таблииа 1. Распределение численности занятых

в здравоохранении по возрастным группам ${ }^{1}$ (в среднем за год)

\begin{tabular}{|c|c|c|c|c|c|c|c|c|c|c|c|c|}
\hline & \multirow{2}{*}{$\begin{array}{c}\text { Занятые } \\
\text { в здра- } \\
\text { воох- } \\
\text { ране- } \\
\text { нии - } \\
\text { всего, } \\
\text { в про- } \\
\text { центах } \\
\text { к итогу }\end{array}$} & \multicolumn{10}{|c|}{ в том числе в возрасте, лет } & \multirow[b]{2}{*}{$\begin{array}{c}\text { Средний } \\
\text { возраст } \\
\text { занятых, } \\
\text { лет }\end{array}$} \\
\hline & & до 20 & $\begin{array}{c}20- \\
24\end{array}$ & $25-29$ & $\begin{array}{c}30- \\
34\end{array}$ & $\begin{array}{c}35- \\
39\end{array}$ & $\begin{array}{c}40- \\
44\end{array}$ & $\begin{array}{c}45- \\
49\end{array}$ & $\begin{array}{c}50- \\
54\end{array}$ & $\begin{array}{c}55- \\
59\end{array}$ & $60-72$ & \\
\hline \multicolumn{13}{|c|}{ Всего } \\
\hline 2000 & 100 & 1,3 & 9,1 & 12,5 & 11,8 & 14,6 & 16,2 & 14,5 & 10,5 & 4,3 & 5,2 & 39,7 \\
\hline 2005 & 100 & 0,5 & 6,5 & 11,4 & 13,3 & 12,1 & 15,6 & 14,8 & 13,0 & 7,4 & 5,3 & 41,2 \\
\hline 2009 & 100 & 0,3 & 6,4 & 10,7 & 11,6 & 12,2 & 13,3 & 16,6 & 14,5 & 9,5 & 5,0 & 42,1 \\
\hline 2010 & 100 & 0,3 & 6,3 & 10,7 & 11,5 & 12,4 & 12,5 & 16,3 & 15,1 & 9,7 & 5,3 & 42,2 \\
\hline \multicolumn{13}{|c|}{ Мужчины } \\
\hline 2000 & 100 & 1,8 & 7,0 & 12,2 & 12,0 & 14,4 & 15,5 & 14,8 & 11,0 & 6,3 & 5,0 & 40,3 \\
\hline 2005 & 100 & 0,2 & 6,4 & 11,8 & 12,0 & 12,3 & 15,7 & 14,4 & 12,2 & 8,0 & 6,9 & 41,8 \\
\hline 2009 & 100 & 0,3 & 7,2 & 12,1 & 10,1 & 10,4 & 12,4 & 15,5 & 14,4 & 11,2 & 6,2 & 42,4 \\
\hline 2010 & 100 & 0,3 & 7,2 & 12,1 & 10,3 & 11,0 & 11,3 & 15,8 & 14,1 & 11,3 & 6,5 & 42,4 \\
\hline \multicolumn{13}{|c|}{ Женщины } \\
\hline 2000 & 100 & 1,2 & 9,5 & 12,6 & 11,7 & 14,6 & 16,3 & 14,5 & 10,4 & 3,9 & 5,2 & 39,5 \\
\hline 2005 & 100 & 0,6 & 6,5 & 11,3 & 13,6 & 12,1 & 15,6 & 14,9 & 13,2 & 7,3 & 4,9 & 41,1 \\
\hline 2009 & 100 & 0,3 & 6,2 & 10,3 & 11,9 & 12,7 & 13,5 & 16,8 & 14,5 & 9,0 & 4,7 & 42,0 \\
\hline 2010 & 100 & 0,3 & 6,1 & 10,3 & 11,7 & 12,7 & 12,8 & 16,5 & 15,4 & 9,2 & 5,0 & 42,2 \\
\hline
\end{tabular}

${ }^{1}$ Справочник Россия в цифрах. М.. Росстат, 2012

Справочник. Здравоохранение в России. М.. Росстат, 2011 


\section{Национальная безопасность - №5(28) • 2013}

ные элементы данной категории, к которым можно отнести квалификацию, профессиональные знания, навыки и умение, возраст, здоровье (физические, умственные способности) уровень образования, стаж работы, ответственность, творческий потенциал. Управление качеством рабочей силы должно быть направлено именно на улучшение и совершенствование данных элементов.

Исходя из указанных структурных элементов, можно проанализировать управление качеством рабочей силы в системе здравоохранения, обеспечивающее качество медицинской помощи (таб.1).

Как следует из данных табл. 1 средний возраст занятых в здравоохранении имеет тенденцию к росту и увеличению, что следует признать негативным фактором, так как значительно растет удельный вес возрастной группы 50-54 лет и 55-59 лет. Удельный вес занятых в возрасте 50-54 года за 2000-2010 г.г. увеличился на 4,6процентных пункта и составил $15,1 \%$, соответственно, 55-59лет — вырос на 5,4 процентных пункта и составил 9,7\%.

Следовательно, суммарный удельный вес данных групп составляет $24,8 \%$, а с учетом категории 60-72года - 30,1\%, что составляет довольно значительную величину.

Далее в таб.2 приводится распределение численности занятых в здравоохранении по уровню образования (таб.2).

Как видно из данных таб.2 около 50\% приходится на лиц, имеющих среднее специальное образование и $30 \%$ - высшее образование, но при этом у женщин численность занятых, имеющих среднее специальное образование - более 50\%, а у мужчин - бо-

Таблииа 2. Распределение численности занятых в здравоохранении по уровню образования (в среднем за год)

\begin{tabular}{|c|c|c|c|c|c|c|c|}
\hline & \multirow[b]{2}{*}{$\begin{array}{c}\text { Занятые } \\
\text { в здравоох- } \\
\text { ранении - } \\
\text { всего }\end{array}$} & \multicolumn{6}{|c|}{ в том числе имеют образование } \\
\hline & & $\begin{array}{c}\text { высшее } \\
\text { профессио- } \\
\text { нальное }\end{array}$ & $\begin{array}{c}\text { среднее } \\
\text { профессио- } \\
\text { нальное }\end{array}$ & $\begin{array}{c}\text { начальное } \\
\text { профессио- } \\
\text { нальное }\end{array}$ & $\begin{array}{c}\text { среднее } \\
\text { (полное) } \\
\text { общее }\end{array}$ & $\begin{array}{c}\text { основное } \\
\text { общее }\end{array}$ & $\begin{array}{c}\text { не имеют } \\
\text { основного } \\
\text { общего } \\
\text { образова- } \\
\text { ния }\end{array}$ \\
\hline \multicolumn{8}{|c|}{ Всего } \\
\hline 2000 & 100 & 28,6 & 43,7 & 6,9 & 14,4 & 5,4 & 1,1 \\
\hline 2005 & 100 & 29,0 & 47,4 & 6,8 & 12,7 & 3,8 & 0,3 \\
\hline 2009 & 100 & 30,9 & 46,1 & 7,9 & 12,0 & 3,0 & 0,2 \\
\hline 2010 & 100 & 30,7 & 46,2 & 8,6 & 11,6 & 2,6 & 0,1 \\
\hline \multicolumn{8}{|c|}{ Мужчины } \\
\hline 2000 & 100 & 48,9 & 20,2 & 6,3 & 16,7 & 6,6 & 1,2 \\
\hline 2005 & 100 & 49,2 & 18,8 & 11,8 & 15,8 & 4,1 & 0,3 \\
\hline 2009 & 100 & 50,2 & 20,9 & 11,6 & 13,8 & 3,4 & 0,1 \\
\hline 2010 & 100 & 48,8 & 21,0 & 13,1 & 13,6 & 3,3 & 0,2 \\
\hline \multicolumn{8}{|c|}{ Женщины } \\
\hline 2000 & 100 & 24,0 & 48,9 & 7,1 & 13,8 & 5,1 & 1,0 \\
\hline 2005 & 100 & 24,6 & 53,7 & 5,7 & 12,0 & 3,8 & 0,3 \\
\hline 2009 & 100 & 26,0 & 52,5 & 6,9 & 11,5 & 2,9 & 0,2 \\
\hline 2010 & 100 & 26,3 & 52,5 & 7,5 & 11,1 & 2,5 & 0,1 \\
\hline
\end{tabular}

${ }^{1}$ Справочник Россия в цифрах. М.. Росстат, 2012 


\section{Экономическое обеспечение национальной безопасности}

Таблица 3. Распределение численности врачей

по квалификационным категориям ${ }^{1}$ (в процентах)

\begin{tabular}{|c|c|c|c|c|c|}
\hline & 1995 & 2000 & 2005 & 2009 & 2010 \\
\hline & \multicolumn{5}{|c|}{ Всего врачей } \\
\hline \multicolumn{6}{|l|}{ Имеют квалификационную категорию: } \\
\hline высшую & 11 & 19 & 26 & 29 & 29 \\
\hline Первую & 20 & 22 & 21 & 19 & 18 \\
\hline Вторую & 8 & 7 & 7 & 6 & 5 \\
\hline \multirow[t]{2}{*}{ Имеют сертификат специалиста } & $\ldots$ & 63 & 80 & 88 & 89 \\
\hline & \multicolumn{5}{|c|}{ Из них работающие в учреждениях, расположенных в сельской местности } \\
\hline \multicolumn{6}{|l|}{ Имеют квалификационную категорию: } \\
\hline высшую & 3 & 7 & 13 & 16 & 17 \\
\hline Первую & 13 & 21 & 24 & 22 & 21 \\
\hline Вторую & 7 & 7 & 6 & 5 & 5 \\
\hline Имеют сертификат специалиста & $\ldots$ & 56 & 78 & 91 & 92 \\
\hline
\end{tabular}

Таблии, 4. Основные показатели здравоохранения (на конеи, года)

\begin{tabular}{|c|c|c|c|c|c|c|c|c|}
\hline & 1992 & 1995 & 2000 & 2005 & 2007 & 2008 & 2009 & 2010 \\
\hline \multicolumn{9}{|c|}{ Численность врачей, человек: } \\
\hline всего, тыс. & 637 & 654 & 680 & 690 & 707 & 704 & 711 & 716 \\
\hline на 10000 человек населения & 42,9 & 44,4 & 46,8 & 48,8 & 49,8 & 49,6 & 50,1 & 50,1 \\
\hline \multicolumn{9}{|c|}{ Численность среднего медицинского персонала, человек: } \\
\hline всего, тыс. & 1709 & 1629 & 1564 & 1530 & 1542 & 1511 & 1518 & 1509 \\
\hline на 10000 человек населения ${ }^{19)}$ & 115 & 111 & 108 & 108 & 109 & 106 & 107 & 106 \\
\hline $\begin{array}{l}\text { Число больничных } \\
\text { учреждений, тыс. }\end{array}$ & 12,6 & 12,1 & 10,7 & 9,5 & 6,8 & 6,5 & 6,5 & 6,3 \\
\hline \multicolumn{9}{|c|}{ Число больничных коек: } \\
\hline всего, тыс. & 1940 & 1851 & 1672 & 1575 & 1522 & 1398 & 1373 & 1339 \\
\hline на 10000 человек населения & 131 & 126 & 115 & 111 & 107 & 99 & 97 & 94 \\
\hline $\begin{array}{c}\text { Число амбулаторно-поликлинических } \\
\text { учреждений, тыс. }\end{array}$ & 20,7 & 21,1 & 21,3 & 21,8 & 18,3 & 15,6 & 15,3 & 15,7 \\
\hline \multicolumn{9}{|c|}{ Мощность амбулаторно-поликлинических учреждений, посещений в смену: } \\
\hline всего, тыс. & 3321 & 3458 & 3534 & 3638 & 3674 & 3651 & 3657 & 3685 \\
\hline на 10000 человек населения & 224 & 235 & 243 & 257 & 259 & 257 & 258 & 258 \\
\hline $\begin{array}{c}\text { Число женских консультаций, детских поликли- } \\
\text { ник, амбулаторий (самостоятельных) и учрежде- } \\
\text { ний, имеющих женские консультации и детские } \\
\text { отделения, тыс. }\end{array}$ & 14,1 & 15,6 & 16,0 & 15,0 & 11,5 & 11,7 & 11,7 & $17,0^{3)}$ \\
\hline $\begin{array}{c}\text { Число коек для беременных женщин } \\
\text { и рожениц, тыс. }\end{array}$ & 113 & 105 & 91 & 82 & 82 & 81 & 81 & 80 \\
\hline Число фельдшерско-акушерских пунктов, тыс. & 46,8 & 45,8 & 44,6 & 43,1 & 39,8 & 39,8 & 38,9 & 37,8 \\
\hline
\end{tabular}

${ }^{1}$ Справочник. Россия в цифрах.М., Росстат,2012

${ }^{2}$ Справочник. Россия в цифрах. М.. Росстат, 2012 
лее $20 \%$. Соответственно, у мужчин высшее образование имеют около50\% занятых, среди женщин - более $25 \%$.

Что касается квалификации, то следует признать положительной тенденцию к росту высшей категории, которая за 10лет выросла на 10 процентных пунктов, при уменьшении первой категории - на 4 процентных пункта (таб.3).

Качество рабочей силы определяет качество медицинской помощи или качественный уровень здравоохранения.

Анализ данных таблицы 4 может свидетельствовать об ухудшении управления качеством рабочей силы в здравоохранении в 2010 г. по сравнению с 2000 г., т. к. снизились показатели числа коек для беременных и рожениц с 91 тыс.коек до 80 тыс., т.е. на 11тыс.коек или на $12 \%$, количество фельдшерско-акушерских пунктов — c 44,6

\section{Библиография}

1. Акопян А. С. Индустрия здоровья: экономика и управление: Пособие для вузов/ А. С. Акопян, Ю. В. Шиленко, Т. В. Юрьева; под ред. Л. Е. Сырцовой.- М.: Дрофа, 2003.

2. Демографический ежегодник России. М., Росстат,2012.

3. Дмитриев Ю. Качество рабочей силы: сущность, мера управления. Минск, 2008.

4. Емельянов А. Продовольственная бедность населения России: истоки и пути преодоления / А. Емельянов // Экономист.— 2003.—№ 10.- с.80.

5. Есипов В.Е., Маховикова Г. А. Внутренние и внешние угрозы продовольственной безопасности России.- СПб.: Изд. СПб. Гос. Университет экономики и финансов, 2005.

6. Журавлев П. В., Одегов Ю. Г., Волгин Н. А. Управление человечески- до 37,8 тыс. т.е. на 6,8 тыс. или на $15 \%$, количество амбулаторно-поликлинических учреждений- с 21,3 тыс. до 15,7 тыс., т.е. на 5,6тыс. или на $26 \%$.

Таким образом, основными задачами в области управления качеством рабочей силы в здравоохранении являются создание модели эффективного управления качеством способностей человека к труду, направленной на повышение качества оказываемой медицинской помощи (медицинских услуг) и разработка мероприятий по непрерывному улучшению. Это позволит повысить качество жизни, а также обеспечить национальную и продовольственную безопасность страны.

При этом главной задачей должно стать научно-обоснованное определение направлений и степени воздействия комплекса факторов на изменение качества способностей человека к труду.

ми ресурсами: опыт индустриально развитых стран. М., Экзамен, 2002.

7. Косаев А.Г. Трудовой потенциал и занятость в условиях интенсификации. М., Наука,1990.

8. Миляева Л. Г. Оценка конкурентоспособности кадров. // ЭКО,2000,№ 3.С.172-175

9. Проект ФЗ «О продовольственной безопасности» М., 1999.

10. Российская социологическая энциклопедия. Под общей редакцией академика РАН Г. В. Осипова. М., 1998

11. Рофе А. О содержании понятий трудовые ресурсы и рабочая сила.// Человек и труд, 1997, № 10.C.23-26

12. Сидоров П. И.

и Ганжин В. Т. Общественное здоровье и социальные недуги. М., АГМА,1996.

13. Справочник. Россия в цифрах. М., Росстат, 2012. 
14. Справочник. Здравоохранение в России. М., Росстат, 2011

15. Старовертов О.В. Условия жизни и межгрупповая мобильность/Экономика и математические методы.- 1997.-№ 4.- с. 64.

16. Хлопова Т. В. Развитие трудового потенциала и конкурентоспособность работников в современных условиях. Методология и практика исследования. Иркутск, БГУЭП, 2004.

17. Экономика труда и социально-трудовые отношения. Под ред. Г. Г. Меликьяна, Р. П. Колосовой. М., МГУ,2000.

\section{References (transliterated)}

1. Akopyan A.S. Industriya zdorov'ya: ekonomika i upravlenie: Posobie dlya vuzov/ A. S. Akopyan, Yu.V. Shilenko, T. V. Yur'eva; pod red. L. E. Syrtsovoi.M.: Drofa, 2003.

2. Demograficheskii ezhegodnik Rossii. M., Rosstat,2012.

3. Dmitriev Yu. Kachestvo rabochei sily: sushchnost', mera upravleniya. Minsk, 2008.

4. Emel'yanov A. Prodovol'stvennaya bednost' naseleniya Rossii: istoki i puti preodoleniya / A. Emel'yanov // Ekonomist.— 2003.—№ 10.- s.80.

5. Esipov V.E., Makhovikova G. A. Vnutrennie i vneshnie ugrozy prodovol'stvennoi bezopasnosti Rossii. - SPb.: Izd. SPb. Gos. Universitet ekonomiki i finansov, 2005.

6. Zhuravlev P. V., Odegov Yu.G.,
Volgin N. A. Upravlenie chelovecheskimi resursami: opyt industrial'no razvitykh stran. M., Ekzamen, 2002.

7. Kosaev A. G. Trudovoi potentsial i zanyatost' v usloviyakh intensifikatsii. M., Nauka,1990.

8. Milyaeva L. G. Otsenka konkurentosposobnosti kadrov. // EKO,2000,№ 3.S.172-175

9. Proekt $\mathrm{FZ} \ll \mathrm{O}$ prodovol'stvennoi bezopasnosti» M., 1999.

10. Rossiiskaya sotsiologicheskaya entsiklopediya. Pod obshchei redaktsiei akademika RAN G. V. Osipova. M., 1998

11. Rofe A. O soderzhanii ponyatii trudovye resursy i rabochaya sila.// Chelovek i trud, 1997, № 10.S.23-26

12. Sidorov P. I. i

Ganzhin V. T. Obshchestvennoe zdorov'e i sotsial'nye nedugi. M., AGMA,1996.

13. Spravochnik. Rossiya v tsifrakh. M., Rosstat,2012.

14. Spravochnik. Zdravookhranenie v Rossii. M., Rosstat,2011

15. Starovertov O. V. Usloviya zhizni i mezhgruppovaya mobil'nost'/Ekonomika i matematicheskie metody.- 1997.№ 4.- - s. 64 .

16. Khlopova T. V. Razvitie trudovogo potentsiala i konkurentosposobnost' rabotnikov v sovremennykh usloviyakh. Metodologiya i praktika issledovaniya. Irkutsk, BGUEP, 2004.

17. Ekonomika truda i sotsial'no-trudovye otnosheniya. Pod red. G. G. Melik'yana, R. P. Kolosovoi. M., MGU,2000. 